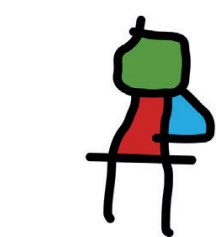

SEICAIP

\section{Allergologia et immunopathologia}

Sociedad Española de Inmunología Clínica, Alergología y Asma Pediátrica

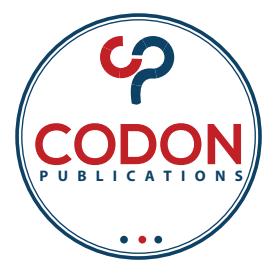

ORIGINAL ARTICLE

OPEN ACCESS (c)

\title{
Prevalence and associated factors of allergic diseases in school children and adolescents aged 6-7 and 13-14 years from two rural areas in Colombia
}

\author{
Sergio Moreno-López ${ }^{\mathrm{a}, \mathrm{b}}$, Lucía C. Pérez-Herrera ${ }^{\mathrm{a}, \mathrm{b}}$, Daniel Peñarandac, \\ Diana C. Hernández ${ }^{\mathrm{d}}$, Elizabeth García ${ }^{\mathrm{b}, \mathrm{e}, \mathrm{f}}$, Augusto Peñaranda ${ }^{\mathrm{a}, \mathrm{b}, \mathrm{g} *}$
}

aOtolaryngology and Allergology Research Groups, Unidad Médico Quirúrgica de Otorrinolaringología (UNIMEQ-ORL), Bogotá, Colombia

${ }^{b}$ Faculty of Medicine, Universidad de Los Andes, Bogotá, Colombia. Address: Cra 1 No. 18A - 12, Bogotá, Colombia

'Division of Otorhinolaryngology, Fundación Universitaria de Ciencias de la Salud - Hospital de San José, Bogotá, Colombia

${ }^{d}$ Faculty of Medicine, Universidad El Bosque, Bogotá, Colombia

eDivision of Pediatric allergies, Department of pediatrics, Hospital Universitario Fundación Santa Fe de Bogotá, Bogotá, Colombia fPediatric allergist and immunologist, Unidad Médico Quirúrgica de Otorrinolaringología (UNIMEQ-ORL), Bogotá, Colombia

${ }^{s}$ Division of Otorhinolaringology, Hospital Universitario Fundación Santa Fe de Bogotá, Bogotá, Colombia

Received 21 August 2020; Accepted 1 December 2020

Available online 1 May 2021

\section{KEYWORDS}

allergic diseases;

allergic rhinitis;

associated factors;

asthma;

atopic dermatitis;

ISAAC phase-III;

prevalence

\begin{abstract}
Introduction: The prevalence of allergic diseases is increasing worldwide, affecting about 30\% of the population in low to middle-income countries. Research trends on allergic diseases within rural pediatric populations of Latin American countries is scarce. This study aimed to determine the prevalence of allergic diseases (allergic rhinitis, asthma, and atopic dermatitis) and their associated factors using the International Study of Asthma and Allergies in Childhood-III (ISAAC-III) questionnaire in school-aged children from two rural municipalities in Colombia.

Materials and methods: This is a cross-sectional study. The ISAAC-III questionnaire was applied to school-aged children attending elementary schools in the municipalities of Soracá and Palmas del Socorro during 2018. The questionnaires were applied to adolescents aged 13-14 years and the parents of 6-7 years old children. Associations were estimated via bivariate and multivariate analysis.
\end{abstract}

*Corresponding author: Augusto Peñaranda, MD, Colombia (Bogotá city), Hospital Universitario Fundación Santa Fe de Bogotá, Avenida 9 No. 116 - 20, office 207. Postal code: 110111, Colombia. Email address: augpenar@gmail.com 
Results: Among 261 school-aged children (58.2\% adolescents), the prevalence of allergic diseases was: allergic rhinitis $11.49 \%(95 \% \mathrm{Cl}: 8.05-15.78)$, asthma $8.81 \%$ (95\% Cl: $5.82-12.7)$, and atopic dermatitis $6.13 \%(95 \% \mathrm{Cl}: 3.69-9.53)$. Associated factors for allergic rhinitis included: female sex (PR: 2.68, 95\% Cl: 1.17-5.26), asthma (PR: 4.69, 95\% Cl: 1.96-8.31), atopic dermatitis (PR: 3.55, 95\% Cl: 1.09-7.83), and higher maternal education (PR: 4.16, 95\% Cl: 1.45-8.25). Conclusions: The prevalence of allergic diseases in this rural pediatric population was lower compared with that of the previous reports from urban populations. Associated factors found in this study support previous studies. Research addressing modifiable environmental associations is so far scarce in Latin America; further studies are needed to reduce the burden of these diseases in rural populations.

(c) 2021 Codon Publications. Published by Codon Publications.

\section{Introduction}

Allergic diseases are the most frequent and expensive chronic diseases in childhood. ${ }^{1}$ The prevalence of these diseases has significantly raised in the last decades, particularly in low to middle-income countries where up to 10 to $30 \%$ of the population has at least one allergic disease. ${ }^{2}$ However, the reasons behind this growth are not entirely established yet and the global distribution of allergic diseases has a substantial variability. ${ }^{3,4}$ This variability could be explained by methodological and population differences, risk factors, and "environmental triggers" that fluctuate by geographic and socioeconomic conditions. ${ }^{3,4}$ The International Study of Asthma and Allergies in Childhood (ISAAC) study was developed to standardize the epidemiological data collection related to allergic rhinitis, asthma, and atopic dermatitis. ${ }^{5}$ In a meta-analysis of the ISAAC-III protocol, the worldwide reported prevalence of asthma, rhinitis, and eczema in children were $14.1 \%, 14.6 \%$, and 7.3\% respectively. ${ }^{5}$ ISAAC-III researchers stated that the prevalence of allergic diseases may be higher in populations with lower socioeconomic conditions. ${ }^{5}$

In Colombia, a low/middle-income country, few studies have been published regarding the prevalence of allergic diseases using the methodology of the ISAAC study. ${ }^{6}$ In Bogotá, Colombia, in children aged 6-7 and 13-14 years, the following risk factors for allergic rhinitis were found: asthma (OR: 3.9, 95\% Cl: 2.8-5.4), atopic dermatitis $(2.3 ; 1.7-3.1)$, acetaminophen consumption in the last year (2.6; 1.4-4.9), high maternal education (1.5; 1.0-2.3), frequent junk food consumption (1.5; 1.2-2.0), and exposure to tobacco smoke $(1.4 ; 1.2-1.7) .{ }^{7}$ However, these studies were conducted in urban populations and few studies address the prevalence and associated factors of allergic diseases in rural areas.

In Ecuador, the prevalence of allergic diseases in school populations in urban versus rural regions was: asthma $9.4 \%$ vs $10.1 \%(p=0.05)$, allergic rhinitis $8.1 \%$ vs $6.4 \%(p=0.02)$, and atopic dermatitis $5.9 \%$ vs $4.7 \%(p=0.06)$, respectively. ${ }^{8}$ Among the rural population included in this study, poor hygiene conditions were associated with an increased risk of respiratory symptoms, as well as poor access to drinking water, and ownership of farm animals. ${ }^{8}$ Likewise, some of the identified risk factors for allergic rhinitis in rural pediatric populations in Bolivia include exposure to farm animals (OR: $1.5,95 \% \mathrm{Cl}: 1.2-1.8)$, ownership of cats $(1.2$; 1.0-1.5), poor domestic conditions (1.5; 1.0-2.2), heavy traffic (1.3;1.0-1.6), and parental tobacco smoke (1.2; 1.0-1.5). ${ }^{9}$ These associations were similar for asthma and atopic dermatitis but did not achieve an adequate level of statistical significance for all variables.

Conversely, some authors state that agriculture and early exposure to poor hygienic conditions could be a protective factor for allergic diseases in rural populations in developed countries. . $^{3,10,11}$ Similarly, researchers in African populations report a lower incidence of allergic diseases in rural areas compared with that of urban areas probably due to early exposure to farm animals during childhood..$^{12,13}$ However, research addressing these factors is so far scarce in low to middle-income countries from Latin America. Therefore, the objective of this study is to establish the trends in the prevalence of allergic diseases and associated risk factors reported by 13-14 years adolescents and parents of 6-7 year old children in two rural populations of Colombia: Palmas del Socorro (Santander) and Soracá (Boyacá). The internationally standardized ISAAC-III questionnaire was applied during a health brigade carried out at the only school of each town between October and November 2018.

\section{Material and Methods}

\section{Study design}

This is an observational, cross-sectional study aimed to determine the trends in the prevalence and associated factors of allergic diseases (allergic rhinitis, asthma, and atopic dermatitis). The study was performed using the ISAAC-III methodology during a health brigade carried out between October and November of 2018. The 6 to 7 years age group received written questionnaires to be responded by parents or legal tutors, while the 13 to 14 years age group received a self-administered written questionnaire. 
All the children included in the study attended schools located in two rural municipalities in Colombia: Soracá (Boyacá), and Palmas del Socorro (Santander).

\section{Study setting}

Soracá (Boyacá) is a municipality with 5353 inhabitants, while Palmas del Socorro (Santander) has 2341 inhabitants. Soracá and Palmas del Socorro have a mean annual temperature of $20^{\circ} \mathrm{C}\left(68^{\circ} \mathrm{F}\right)$, and their average humidity is $83 \%$. Both the municipalities share common geographical characteristics such as their location between five to six degrees latitude of the Equator. ${ }^{14}$ Thus, both Soracá and Palmas could be considered as tropical or equatorial climate municipalities. Moreover, both municipalities are agricultural low-income communities with high poverty index and high rates of rural population located in small settlements outside the main towns. ${ }^{15,16}$ These municipalities have no or limited access to hygiene services and drinking water; more than $90 \%$ of the houses do not have sewage systems, and access to health services is inadequate..$^{15,16}$ Overall, these conditions encourage house dust mites and intestinal helminth infections, two of the most important environmental components of allergic diseases in the Tropics. ${ }^{3}$ Indeed, the most frequent diseases described in the municipal reports of the two municipalities are parasitic diseases and acute respiratory infections. ${ }^{15,16}$

Therefore, this population is considered a representative sample to assess the sociodemographic characteristics and frequency of allergic diseases in pediatric rural LatinAmerican populations. In both the municipalities, there is only one first-level medical center for the whole community, and only one general practitioner is available for each clinic. No information on allergic diseases was previously described in the public health municipal reports, ${ }^{15,16}$ and the sample was selected from this general population who had not been treated or diagnosed for allergic diseases. This was the first diagnostic and epidemiological approach to allergic diseases in children and adolescents in both communities. These conditions granted that the presence of allergic diseases in the study population was not overestimated.

\section{Participants}

The sample size was established considering the data from previous studies that describe a prevalence of asthma, allergic rhinitis, and atopic dermatitis of $7.29 \%, 22.6 \%$, and $13.89 \%$, respectively. ${ }^{6,717}$ Moreover, an estimation error of $5 \%$, as well as the population projections of 984 subjects reported by the Colombian National Administrative Department of Statistics ${ }^{15,16}$ were considered in the following formula ${ }^{18}$ :

$$
n=\frac{N^{*} Z_{1-\frac{\alpha}{2}}{ }^{*} p^{*}(1-p)}{d^{2 *}(N-1)+Z_{1-\frac{\alpha}{2}}}
$$

Where $\mathrm{N}$ is the population size, $\mathrm{d}$ is the estimation error, and $p$ is the prevalence of each disease. Considering a significance level of $1 \%$, a statistical power of $80 \%,{ }^{5}$ and an adjustment for probable losses (5\%), the estimated sample size was 245 patients. No independent sample sizes were calculated considering that both municipalities have similar geographical and socio-demographic conditions, and that the sample size accounted for the majority of the pediatric population. The study sample was made up of 261 children aged 6-7 and 13-14 years. The selection of individuals was based on a simple random sampling selection through negative coordination method to minimize selection bias, and achieve a uniform, and random sample selection. ${ }^{18}$

One week before the health brigade was performed at the only two schools in the municipalities, the researchers visited both schools. With the support of the school principals, the researchers explained the purpose of the study to the parents or legal guardians of the children during an academic parent conference. A letter explaining the objective, risks, and benefits of the study as well as a written informed consent form was provided to parents, or legal guardians during this visit. The voluntary participation of children was respected. Once the purpose of the study was explained, the informed consent was obtained from all the included participants and their parents. Children, parents, or school directors were not informed about study hypotheses to prevent their prompt response to the problems and risk factors we assessed.

\section{Demographic and clinical questionnaire}

The demographic and clinical questionnaire applied is a survey that sought information about previously described risk factors for allergic diseases in the scientific literature. The information about the length and height of the adolescents was obtained attaching to calibration guidelines to achieve proper accuracy and reliability levels of the childhood growth measurement equipment. ${ }^{19}$ Trained medical researchers gathered this information adhering to WHO recommendations. ${ }^{19}$

\section{ISAAC-III questionnaire}

Following ISAAC-III Phase objectives, this study aimed to assess trends in the prevalence of asthma, allergic rhinitis, and atopic dermatitis in this rural pediatric population, and examine the associated factors' hypotheses at an individual level. ISAAC-III questionnaire has been adapted and validated to the Spanish language, ${ }^{20}$ is easily applicable, and inexpensive considering the difficulties of pursuing research budget to perform studies in rural populations, particularly in low to middle-income countries. Besides, this questionnaire has adequate reproducibility, and allows comparisons between populations. ${ }^{20}$ The researchers applied the questionnaires based on the ISAAC-III manual, and all the participants provided an autonomous response of the questionnaire. ${ }^{5,20}$ Trained researchers with wide experience in the structure to the questionnaires assisted all the adolescents who asked for help to clarify their doubts about some questions. 
The ISAAC-III questionnaire assesses the prevalence of asthma, rhinitis, and eczema or atopic dermatitis symptoms over a 12-month period. ${ }^{20}$ For the purpose of this study and adhering to ISAAC-III recommendations, ${ }^{20}$ the prevalence of allergic diseases were defined as follows: allergic rhinitis symptoms were based on a positive response to: "In the past 12 months, have you had a problem with sneezing/ runny/blocked nose when you did not have a cold/flu?"; asthma symptoms were defined as a positive answer to: "Have you ever had wheezing/whistling in the chest in the last 12 months?"; atopic dermatitis symptoms were based on a positive response to three questions: "Did you ever have an itchy/rash that was coming and going for at least 6 months?", "Did you have this itchy/rash at any time in the last 12 months?", and "Has this itchy/rash at any time affected any of the following places: folds of the elbows, behind the knees, in front of the ankles, under the buttocks, or around the neck/ears/eyes?".

Moreover, questions assessing environmental factors which have been previously associated to allergic diseases, as well as dietary, and behavioral habits, were added from the Spanish-language environmental questionnaire used in the ISAAC-III study. ${ }^{20}$

\section{Statistical analysis}

Stata16MP was used for the statistical analysis and the "a priori" significance level for the comparisons was $5 \%$. Frequencies and percentages were calculated for qualitative variables, as well as measures of central tendency (mean and median) and dispersion (standard deviation and interquartile range) along with maximum and minimum values for quantitative variables. BMI categories were classified meeting the international categories established by the WHO Child Growth guidelines implemented in a .do file of Stata. ${ }^{21}$

The prevalence of each of the allergic diseases in the population and the 95\% confidence intervals were calculated considering the sample weights of the above-mentioned sample selection method. A bivariate analysis was conducted to assess the association between each allergic disease and their covariates. The predictors of the model were selected considering biological plausibility reported by previous studies, and the possible statistical association within the variables in the study. The modifying effect of these covariates was determined and the variables showing stronger associations $(p<0.20)$, and clinically relevant variables, were selected for the multivariate analysis. A multivariate analysis based on a logistic regression analysis was performed to find the adjusted effect of the possible covariates. Considering the frequency of each allergic disease and the sample size, prevalence ratios were adjusted to determine the factors associated with the frequency of allergic rhinitis. ${ }^{22}$ Statistical significance for the multivariate models was defined as $\mathrm{p}<0.05$.

Ethics committee approval was received for this study from the ethics committee of the Hospital Universitario Fundación Santa Fe de Bogotá (CCEI-9737-2018), and the Hospital de San José (act number 500, DI-I-0901-19) according to the Helsinki Declaration. Informed Consent was obtained from all the participants and their parents. No incentives were offered for study participation.

\section{Results}

A total of 261 individuals were included, of which $58.2 \%$ $(n=152)$ were adolescents. The description of the socio-demographic characteristics of the study population is found in Table 1. A higher percentage of female population (54.8\%) was found. Most of the children were from Soracá (68.6\%), and $59 \%$ of the study population lived in rural areas located in small settlements outside the main towns.

\section{Prevalence of allergic diseases}

Table 2 shows the prevalence of allergic diseases in the study population. Adolescents were more likely to report allergic rhinitis (13.16\%) and asthma (12.5\%) symptoms than by the parents of children from the 6-7 years age group (9.17\% and $3.67 \%$, respectively). Overall, the prevalence of allergic diseases was higher in adolescents, except for atopic dermatitis.

\section{Associated factors}

The possible factors associated with allergic rhinitis in the study population were established based on a logistic regression model. The Prevalence Ratio (PR) for each assessed factor with its corresponding confidence intervals are shown in Table 3. Associated factors for allergic rhinitis found in the study population include female sex $(P R=2.68$; $\left.I_{95 \%}[1.17-7.12]\right)$, asthma $\left(P R=4.69 ; I_{95 \%}[1.96-8.31]\right)$ and atopic dermatitis $\left(P R=3.55 ; I_{95 \%}[1.09-7.83]\right)$, and higher maternal education $\left(P R=4.16 ; I_{95 \%}[1.45-8.25]\right)$. Previous studies report that atopic dermatitis and asthma are the associated factors for allergic rhinitis ${ }^{23}$; thus these variables were included in the statistical models. Despite allergic diseases are closely related, previous models include atopic dermatitis and asthma as independent variables. The statistical analysis of mediation revealed that these variables did not have a significant impact on the final results.

Furthermore, the factors associated with asthma are shown in Table 4. Associated factors for asthma found by the models include Palmas of Socorro $\left(P R=4.24\right.$; $I_{95 \%}[1.87-$ 7.12]), and allergic rhinitis ( $\left.P R=5.43 ; \quad I C_{95 \%}[2.46-8.28]\right)$. Regarding the diagnosis of the factors, regression model, linearity tests, and goodness-of-fit tests of Hosmer and Lemeshow were carried out. No collinearity problems were found. Likewise, no extreme or influential values that could affect the model were found during the evaluation of deviance residuals and leverage points. The small sample size of children with atopic dermatitis $(n=16)$ was not enough to perform the logistic regression model in order to assess associations to achieve the statistical effect size.

\section{Discussion}

This study aimed to determine the prevalence trends and associated factors of allergic diseases in a rural pediatric sample from Colombia using the ISAAC-III methodology. Our findings contribute to the understanding of modifiable 
Table 1 Baseline demographic and clinical characteristics of the study population.

\begin{tabular}{|c|c|c|}
\hline \multirow[b]{2}{*}{ Variables } & \multicolumn{2}{|c|}{$N=261$} \\
\hline & $\mathbf{n}$ & Percentage (\%) \\
\hline Sex, female/male & $143 / 118$ & $54.8 / 45.2$ \\
\hline Age group & & 261 \\
\hline 6 to 7 years & 109 & 41.8 \\
\hline 13 to 14 years & 152 & 58.2 \\
\hline Age in years ${ }^{a}$ & $11.3(3.3)$ & $13.2(4.9-15.4)$ \\
\hline \multicolumn{3}{|l|}{ Municipality } \\
\hline Soracá, Boyacá & 179 & 68.6 \\
\hline $\begin{array}{l}\text { Palmas del Socorro, } \\
\text { Santander }\end{array}$ & 82 & 31.4 \\
\hline \multicolumn{3}{|l|}{ Residency area } \\
\hline Main rural towns & 107 & 41.0 \\
\hline $\begin{array}{l}\text { Small settlements near main } \\
\text { towns }\end{array}$ & 154 & 59.0 \\
\hline $\mathrm{BMI}^{\mathrm{a}}$ & $19(5.58)$ & $18(9.5-75.7)$ \\
\hline \multicolumn{3}{|l|}{ Mother's educational level } \\
\hline Primary education & 107 & 41.0 \\
\hline Secondary education & 118 & 45.2 \\
\hline Higher education & 36 & 13.8 \\
\hline \multicolumn{3}{|l|}{ Exercise frequency per week } \\
\hline Occasionally or none & 64 & 24.5 \\
\hline One to two times per week & 141 & 54.0 \\
\hline Three or more times per week & 54 & 20.7 \\
\hline No information & 2 & 0.8 \\
\hline \multicolumn{3}{|l|}{ Exercise frequency per day } \\
\hline Less than $1 \mathrm{~h}$ & 35 & 13.4 \\
\hline 1 to $2 \mathrm{~h}$ & 121 & 46.4 \\
\hline 3 to $4 \mathrm{~h}$ & 75 & 28.7 \\
\hline $5 \mathrm{~h}$ or more & 30 & 11.5 \\
\hline \multicolumn{3}{|l|}{ Time watching television } \\
\hline Less than $1 \mathrm{~h}$ per day & 32 & 12.2 \\
\hline $1-2 \mathrm{~h} /$ day in a normal week & 121 & 46.3 \\
\hline $3-4 \mathrm{~h} /$ day in a normal week & 75 & 28.7 \\
\hline $\begin{array}{l}\text { More than } 5 \mathrm{~h} / \text { day in a normal } \\
\text { week }\end{array}$ & 33 & 12.6 \\
\hline \multicolumn{3}{|l|}{ Passive exposure to tobacco smoke } \\
\hline Maternal smoking & 4 & 1.5 \\
\hline \multirow[t]{2}{*}{ Paternal smoking } & 17 & 6.5 \\
\hline & 29 & 11.1 \\
\hline \multicolumn{3}{|l|}{ Cooking fuel } \\
\hline Electricity & 27 & 10.3 \\
\hline Gas & 179 & 68.6 \\
\hline Wood or Coal & 103 & 39.5 \\
\hline \multicolumn{3}{|c|}{ Traffic on the street of the household } \\
\hline None & 76 & 29.1 \\
\hline Occasional & 74 & 28.4 \\
\hline Frequently during the day & 76 & 29.1 \\
\hline Most of the day & 64 & 24.5 \\
\hline \multicolumn{3}{|l|}{ Current exposure to pets } \\
\hline Dogs & 212 & 81.2 \\
\hline Cats & 152 & 58.2 \\
\hline \multicolumn{3}{|l|}{ Acetaminophen consumption } \\
\hline Never & 34 & 13.0 \\
\hline At least once per year & 84 & 32.2 \\
\hline At least once per month & 141 & 54.0 \\
\hline No information & 2 & 0.8 \\
\hline \multicolumn{3}{|l|}{ Fast food consumption } \\
\hline Less than one time per week & 198 & 75.9 \\
\hline One or two times per week & 49 & 188 \\
\hline Three or more times per week & 8 & 3.1 \\
\hline No information & 6 & 2.3 \\
\hline
\end{tabular}

avalues are expressed in mean (SD) and median (p. 25-p. 75). environmental factors in allergic diseases in Latin American pediatric populations. Among the sociodemographic characteristics found in the study population, we stand out that up to $59 \%$ of them live in small settlements outside the main towns. This scenario challenges access to health and basic hygiene services and this can increase the risk of parasitic diseases. Apparently, helminthic parasitic infections prove protective immunity against some allergic diseases mediated by type 2 immune mechanisms that modulate the allergic inflammatory response. ${ }^{24,25}$

The main economic activities in Soracá and Palmas are livestock and agriculture, so most of the children were probably exposed to farm animals in their early childhood. Studies in similar African populations report a lower incidence of allergic diseases in rural areas probably due to early exposure to farm animals during childhood. ${ }^{12,13}$ Early exposure to farm animals, along with pet ownership (dogs $81.2 \%$ and/or cats $58.2 \%$ ), has been stated as a protective factor for the development of allergies in developed countries. ${ }^{10,26,27}$ Besides, clinical trials describe that this protective effect could be mediated by early exposure to micro-organisms. ${ }^{28}$ Conversely, in low to middle-income countries some authors suggest that agricultural activities and early exposure to farm animals are associated with poverty, inadequate hygiene conditions, and environmental risk factors that contribute to the development of allergic diseases. ${ }^{8,9}$

Among 261 children and adolescents included in this study, the most frequently reported allergic disease was allergic rhinitis. However, this frequency is lower compared with that of the urban pediatric population from Bogotá, Colombia, which varies from $17.2 \%$ (95\% Cl: 15.9-18.5) in children to $24.9 \%(95 \% \mathrm{Cl}: 23.6-26.3)$ in adolescents. ${ }^{7}$ This lower frequency of allergic rhinitis in the rural population could be related to variations in the distribution of triggers and risk factors for allergic diseases. Bogotá is located four degrees latitude of the Equator, which is similar to Soracá and Palmas, but the climate, humidity, and socioeconomic conditions of Bogotá are different. ${ }^{3}$ However, there is no information assessing allergic diseases in urban populations closer to the geographic areas included in this study. Thus, geographical and environmental conditions could account for these differences.

Regarding the frequency of asthma found in our study population, there is a substantial difference in the frequency of this disease in the group of children aged 6-7 years, of $3.67 \%$, compared with that of the group of adolescents aged 13 to 14 years who reported a frequency of $12.50 \%$. Studies in urban populations of tropical countries report a prevalence of 10.9\% (SD: 8.4) in children aged 6 to 7 years and $13.0 \%$ (SD: 7.1 ) in adolescents aged 13 to 14 years. $^{3}$ Thus, the frequency of asthma found in adolescents is similar to that reported in the literature, but the frequency of asthma in the group of children (aged 6-7 years) found in this study is particularly lower than the previous rural and urban reports. Some authors state that the adolescents' perception of their own symptoms could be a better marker of an allergic disease compared with the parents' perception of symptoms of their children. ${ }^{29}$ The higher prevalence of asthma symptoms in the adolescents included in this study could be explained by this phenomenon. 
Table 2 Prevalence of allergic diseases in the study population.

\begin{tabular}{|c|c|c|c|c|c|c|c|c|c|}
\hline \multirow[b]{2}{*}{ Allergic disease } & \multicolumn{3}{|c|}{$\begin{array}{l}\text { Children aged } 6 \text { to } 7 \text { years } \\
\qquad(n=109)\end{array}$} & \multicolumn{3}{|c|}{$\begin{array}{c}\text { Adolescents aged } 13 \text { to } 14 \\
\text { years }(n=152)\end{array}$} & \multicolumn{3}{|c|}{ Total $(n=261)$} \\
\hline & $\mathrm{n}$ & Percentage (\%) & $95 \% \mathrm{Cl}$ & $\mathrm{n}$ & Percentage (\%) & $95 \% \mathrm{Cl}$ & $\mathrm{n}$ & Percentage (\%) & $95 \% \mathrm{Cl}$ \\
\hline Allergic rhinitis & 10 & 9.17 & $(4.81-15.6)$ & 20 & 13.16 & $(8.49-19.20)$ & 30 & 11.49 & $(8.05-15.78)$ \\
\hline Asthma & 4 & 3.67 & $(1.25-8.48)$ & 19 & 12.50 & (7.96-18.45) & 23 & 8.81 & (5.82-12.7) \\
\hline Atopic dermatitis & 8 & 7.34 & (3.53-13.3) & 8 & 5.26 & $(2.51-9.68)$ & 16 & 6.13 & (3.69-9.53) \\
\hline \multicolumn{10}{|c|}{ Presence of allergic rhinitis in combination with } \\
\hline Asthma & 2 & 1.83 & - & 8 & 5.26 & - & 10 & 3.83 & - \\
\hline Atopic dermatitis & 2 & 1.83 & - & 4 & 2.63 & - & 6 & 2.30 & - \\
\hline \multicolumn{10}{|c|}{ Presence of asthma in combination with } \\
\hline Atopic dermatitis & 1 & 0.92 & - & 2 & 1.32 & - & 3 & 1.15 & - \\
\hline
\end{tabular}

Table 3 Associated factors for allergic rhinitis.

\begin{tabular}{|c|c|c|c|c|}
\hline \multirow[b]{2}{*}{ Variable } & \multicolumn{2}{|c|}{ Bivariate analysis $^{b}$} & \multicolumn{2}{|c|}{ Multivariate analysis $^{\mathrm{b}}$} \\
\hline & $\mathrm{PR}^{\mathrm{a}}$ & $95 \% \mathrm{Cl}$ & $\mathrm{PR}^{\mathrm{a}}$ & $95 \% \mathrm{Cl}$ \\
\hline Age in years & 1.08 & $(0.96-1.20)$ & 1.09 & $(0.95-1.25)$ \\
\hline \multicolumn{5}{|l|}{ Sex } \\
\hline Female & 1.92 & $(0.92-3.69)$ & 2.68 & $(1.17-5.26)$ \\
\hline \multicolumn{5}{|l|}{ Municipality } \\
\hline Palmas del Socorro & 1.67 & $(0.84-3.05)$ & 1.02 & $(0.40-2.43)$ \\
\hline \multicolumn{5}{|l|}{ Residency area } \\
\hline Small settlements near main towns & 0.63 & $(0.31-1.22)$ & 0.87 & $(0.34-2.11)$ \\
\hline \multicolumn{5}{|l|}{ Asthma } \\
\hline Yes & 5.17 & $(2.74-7.90)$ & 4.69 & $(1.96-8.31)$ \\
\hline \multicolumn{5}{|l|}{ Atopic dermatitis } \\
\hline Yes & 3.83 & $(1.70-6.55)$ & 3.55 & $(1.09-7.83)$ \\
\hline \multicolumn{5}{|l|}{ Current exposure to cats } \\
\hline Yes & 0.69 & $(0.35-1.38)$ & 0.81 & $(0.33-1.89)$ \\
\hline \multicolumn{5}{|l|}{ Current exposure to dogs } \\
\hline Yes & 0.92 & $(0.38-2.03)$ & 0.89 & $(0.28-2.54)$ \\
\hline \multicolumn{5}{|l|}{ Tobacco smoke exposure } \\
\hline One or more smokers in the household & 1.60 & $(0.63-3.46)$ & 1.09 & $(0.32-3.21)$ \\
\hline \multicolumn{5}{|l|}{ Acetaminophen consumption } \\
\hline Yes & 1.99 & $(0.95-3.80)$ & 1.84 & $(0.80-3.82)$ \\
\hline \multicolumn{5}{|l|}{ Traffic on the street of the household } \\
\hline Yes & 1.12 & $(0.51-2.29)$ & 1.09 & $(0.40-2.69)$ \\
\hline \multicolumn{5}{|l|}{ Mother's educational level } \\
\hline Secondary education & 2.13 & $(0.92-4.14)$ & 2.16 & $(0.80-4.87)$ \\
\hline Higher education & 3.78 & $(1.68-6.36)$ & 4.16 & $(1.45-8.25)$ \\
\hline
\end{tabular}

aPR: Prevalence Ratio.

'Log-likelihood of the model: -72.118 8; AIC:172.2363; BIC: 221.814; Log-likelihood intercept only: -92,364.

Bolded values highlight statistically significant associated variables.

Moreover, the local public health reports of both the municipalities describe a high frequency of parasitic diseases in pediatric population..$^{16,30}$ The low frequency of asthma found in this study in the population of children aged 6-7 years could also be explained by the fact that this age group has a higher frequency of parasitic diseases..$^{31,32}$ Researchers in rural children from Perú have also showed that age is an important risk factor for parasitic infection: the odds of parasitic infection increase in children aged $<7$ years, and a decrease in adolescent population. ${ }^{33}$ Hence, children aged 6-7 years may be more likely to have parasite infection and have different trends in asthma prevalence.
It has been described that in tropical rural populations parasitic diseases can increase (Ascaris Lumbricoides) or decrease (Ancylostoma) the risk of asthma symptoms. ${ }^{11,24,34}$

In the Northern Coast of Colombia, where ascariasis is an endemic disease, Zakzuk et al. state that ascariasis decreases asthma symptoms via IgE modulation depending on the severity of the infection. ${ }^{11} \mathrm{~A}$ high burden of parasites can be a protective factor probably due to the pulmonary state of ascariasis. ${ }^{11}$ The differences in our results could be related to different degrees of parasitic severity in this population. Besides, geographical, cultural, and climate differences between the Northern coast of Colombia, 
Table 4 Associated factors for asthma.

\begin{tabular}{|c|c|c|c|c|}
\hline \multirow[b]{2}{*}{ Variable } & \multicolumn{2}{|c|}{ Bivariate analysis $^{b}$} & \multicolumn{2}{|c|}{ Multivariate analysis $^{\mathrm{b}}$} \\
\hline & $\mathrm{PR}^{\mathrm{a}}$ & $95 \% \mathrm{Cl}$ & $\mathrm{PR}^{\mathrm{a}}$ & $95 \% \mathrm{Cl}$ \\
\hline Age in years & 1.08 & $(0.96-1.20)$ & 1.20 & $(0.98-1.41)$ \\
\hline \multicolumn{5}{|l|}{ Sex } \\
\hline Female & 0.90 & $(0.40-1.90)$ & 0.64 & $(0.23-1.67)$ \\
\hline \multicolumn{5}{|l|}{ Municipality } \\
\hline Palmas del Socorro & 6.19 & $(2.68-12.20)$ & 4.24 & $(1.87-7.12)$ \\
\hline \multicolumn{5}{|l|}{ Residency area } \\
\hline Small settlements near main towns & 0.79 & $(0.35-1.68)$ & 0.76 & $(0.26-2.01)$ \\
\hline \multicolumn{5}{|l|}{ Allergic rhinitis } \\
\hline Yes & 5.92 & $(2.89-9.98)$ & 5.43 & $(2.46-8.28)$ \\
\hline \multicolumn{5}{|l|}{ Atopic dermatitis } \\
\hline Yes & 2.30 & $(0.70-5.73)$ & 1.91 & $(0.39-5.9)$ \\
\hline \multicolumn{5}{|l|}{ Current exposure to cats } \\
\hline Yes & 0.93 & $(0.41-1.98)$ & 1.09 & $(0.38-2.76)$ \\
\hline \multicolumn{5}{|l|}{ Current exposure to dogs } \\
\hline Yes & 2.43 & $(0.60-8.01)$ & 1.95 & $(0.36-6.28)$ \\
\hline \multicolumn{5}{|l|}{ Tobacco smoke exposure } \\
\hline $\begin{array}{l}\text { One or more smokers in the household } \\
\text { Acetaminophen consumption }\end{array}$ & 1.20 & $(0.36-3.40)$ & 0.86 & $(0.19-3.15)$ \\
\hline Yes & 1.60 & $(0.70-3.38)$ & 0.92 & $(0.33-2.3)$ \\
\hline \multicolumn{5}{|l|}{ Traffic on the street of the household } \\
\hline Yes & 0.45 & $(0.20-0.98)$ & 0.41 & $(0.14-1.15)$ \\
\hline \multicolumn{5}{|l|}{ Mother's educational level } \\
\hline Secondary education & 1.41 & $(0.57-3.16)$ & 1.10 & $(0.36-2.89)$ \\
\hline Higher education & 2.08 & $(0.70-4.96)$ & 1.80 & $(0.47-5.04)$ \\
\hline
\end{tabular}

apR: Prevalence Ratio.

'Log-likelihood of the model: 55,762; AIC:139,524; BIC: 189.102; Log-likelihood intercept only: $-77,26$.

Bolded values highlight statistically significant associated variables.

and Soracá-Palmas may also account for these variations. However, our study did not assess these associations, and studies regarding these issues in rural pediatric groups are needed.

The frequency of atopic dermatitis found in the group of children aged 6-7 years was $7.34 \%(95 \% \mathrm{Cl}: 3.53-13.3)$ and in adolescents $5.26 \%(2.51-9.68)$. This frequency is higher than the previous reports from urban regions of Colombia which reports a prevalence of $4.6 \%(95 \% \mathrm{Cl}: 3.2-6.0)$ in the 5-11 years age group and $4.2 \%(95 \% \mathrm{Cl}: 3.1-5.3)$ in the adolescents group. ${ }^{35}$ Meanwhile, in rural areas in high-income countries such as Finland and England, the frequency of atopic dermatitis found in this study is low. ${ }^{36}$ The frequency of dermatitis reported here is lower compared with that of rural populations of developing countries like Bolivia, with a frequency of $8.5 \%(p=0.59)^{9}$ and Ecuador with a frequency of $4.7 \%(p=0.06) .{ }^{8}$ These differences could be explained by the influence of modifiable local environmental factors and the heterogeneous geographical distribution of allergens.

The factors associated with allergic diseases found in this study are consistent with previous literature. An association was found between female sex and allergic rhinitis (PR: 2.68, 95\% Cl 1.17-5.26). Similarly, the international ISAAC-III report of Latin American countries established a lower frequency of rhinitis and asthma symptoms in boys, compared with tht of girls in the 6-7 years group. ${ }^{5}$ However, more girls than boys were found to have symptoms of allergic disease in the older age group. ${ }^{5}$ We also stand out that these differences may fluctuate between countries and geographical conditions, so it is essential to conduct these studies in different population settings.

An interaction was also found between asthma (PR: 4.69, 95\% Cl: 1.96-8.31) and atopic dermatitis (PR: 3.55, 95\% Cl: 1.09-7.83) as associated factors for allergic rhinitis. This association has been explained by the close relationship between allergic diseases as well as the concept of allergy as a systemic disease that primarily affects the nasal mucosa, respiratory tract, and skin. ${ }^{17}$ Furthermore, the coexistence of allergic rhinitis with allergic diseases such as asthma and allergic conjunctivitis has been frequently described. 6,7,17 We highlight that the association of allergic rhinitis with asthma requires special attention as an increased risk of developing asthmatic crises has been described in patients with uncontrolled allergic rhinitis symptoms. ${ }^{23}$

The association between higher maternal education and allergic rhinitis (PR: 4.16, 95\% Cl: 1.45-8.25) has also been described in previous studies. ${ }^{37}$ Moreover, we found a frequency of $21.9 \%$ of junk food consumption and $19.5 \%$ of passive tobacco exposure, which are low compared with that of urban pediatric populations. ${ }^{38,39}$ Likewise, the frequency of sedentarism found was $24.5 \%$, which is lower compared with that of the previous reports in urban populations. ${ }^{40}$ However, we stand out that almost $75 \%$ of the population reported that they spent 1 to $4 \mathrm{~h}$ per day watching television, which is an indicator of a sedentary lifestyle. 
Previous studies have linked all these variables to a higher risk for the development of allergic diseases., ${ }^{7,38}$ Finally, an association was found between asthma and living in Palmas del Socorro (RR: 4.24, 95\% Cl: 1.87-7.12). Nevertheless, the wide confidence interval of this association shows that the sample size of children with asthma is small and knowledge about the effect of the sample size could not be inferred.

Within the strengths of this study, we stand out that this was the first diagnostic approach on these rural populations. Selection bias control was conducted through a simple random sampling, and no significant differences were expected between the population attending the educational institutions included in the study and the remainder of the teenage population in these rural environments. Data collection was performed by trained medical practitioners with extensive prior experience in the application of the ISAAC-questionnaire. All possible outcome-modifying factors were adjusted during the statistical analysis to minimize confounding biases. The diagnosis of allergic diseases represents a research challenge worldwide due to the lack of a gold standard. ${ }^{5,20}$ We are aware of ISAAC diagnostic limitations based on the definitions of allergic diseases through self-reporting of symptoms. ${ }^{5,20}$ However, considering that our study population is exposed to healthcare access barriers, this approach allowed us to avoid biases related to the under-diagnosis and heterogeneity in medical practice. ${ }^{9}$

Among the limitations of the study we highlight that there is still a lack of information related to the epidemiology of allergic diseases in rural populations; this is an important barrier to carry out homogeneous comparisons. Besides, ISAAC-questionnaire design can be susceptible to recall bias, and all the strategies recommended by ISAAC were considered to minimize these probable biases. ${ }^{20} \mathrm{We}$ highlight that despite the difficulties in reaching rural populations, further studies using a larger sample size are also needed. This information is essential for future research and for the development of health campaigns aimed to identify modifiable environmental factors in rural populations. Further studies are needed to explore the frequency and associated factors in these populations in low to middle-income countries.

\section{Conclusions}

A lower prevalence of allergic diseases was established in the rural populations compared with that of previous studies on similar populations. The associated factors found in this study are similar to previous reports. These findings highlight the crucial role of geographical and local environmental characteristics and allergen distribution in the prevalence of allergic diseases. There are still few studies worldwide reporting the prevalence of these diseases in rural populations of low to middle-income countries in Latin America. The reported information is useful for future research, and health campaigns focused on modifiable environmental factors in rural populations.

\section{Acknowledgments}

Special thanks to Emily Harmon and Eliana Parra for their writing assistance and technical editing. We show our gratitude to Mario Jacome, and the School Principals from both the institutions: "Institución Educativa Simón Bolivar" in Soracá (Boyacá) and “Colegio Departamental La Inmaculada" in Palmas del Socorro (Santander). Their support during the fieldwork was essential for data collection.

\section{References}

1. Pinto Pereira LM, Jackman J, Figaro N, Babootee N, Cudjoe G, Farrell $\mathrm{S}$, et al. Health burden of co-morbid asthma and allergic rhinitis in West Indian children. Allergol Immunopathol (Madr). 2010;38(3):129-34. https://doi.org/10.1016/j.aller. 2009.09.002

2. Pawankar R. Allergic diseases and asthma: a global public health concern and a call to action. World Allergy Organ J. 2014;7(1):1-3. https://doi.org/10.1186/1939-4551-7-12

3. Caraballo L, Zakzuk J, Lee BW, Acevedo N, Soh JY, SánchezBorges $\mathrm{M}$, et al. Particularities of allergy in the tropics. World Allergy Organ J. 2016;9(20):1-44. https://doi.org/10.1186/ s40413-016-0110-7

4. Haahtela T, Holgate S, Pawankar R, Akdis CA, Benjaponpitak S, Caraballo $\mathrm{L}$, et al. The biodiversity hypothesis and allergic disease: world allergy organization position statement. World Allergy Organ J. 2013;6(1):1. https://doi.org/10.1186/ 1939-4551-6-3

5. Mallol J, Crane J, von Mutius E, Odhiambo J, Keil U, Stewart A, et al. The International Study of Asthma and Allergies in Childhood (ISAAC) phase three: a global synthesis. Allergol Immunopathol (Madr). 2013 Mar;41(2):73-85. https://doi.org/ 10.1016/j.aller.2012.03.001

6. Dennis RJ, Caraballo L, García E, Rojas MX, Rondon MA, Pérez A, et al. Prevalence of asthma and other allergic conditions in Colombia 2009-2010: a cross-sectional study. BMC Pulm Med. 2012;12(1):1. https://doi.org/10.1186/1471-2466-12-17

7. Peñaranda A, Aristizabal G, García E, Vásquez C, RodríguezMartinez CE. Rhinoconjunctivitis prevalence and associated factors in school children aged 6-7 and 13-14 years old in Bogota, Colombia. Int J Pediatr Otorhinolaryngol. 2012;76(4):530-5. https://doi.org/10.1016/j.ijporl.2012.01.010

8. Cooper PJ, Vaca M, Rodriguez A, Chico ME, Santos DN, Rodrigues LC, et al. Hygiene, atopy and wheeze - eczema rhinitis symptoms in schoolchildren from urban and rural Ecuador. Thorax. 2014;69(3):32-9. https://doi.org/10.1136/ thoraxjnl-2013-203818

9. Solis-Soto MT, Patiño A, Nowak D, Radon K. Association between environmental factors and current asthma, rhinoconjunctivitis and eczema symptoms in school-aged children from Oropeza Province - Bolivia: a cross-sectional study. Environ Heal A Glob Access Sci Source. 2013;12(1):1-9. https:// doi.org/10.1186/1476-069X-12-95

10. Wong GW, Chow CM. Childhood asthma epidemiology: insights from comparative studies of rural and urban populations. Pediatr Pulmonol. 2008;43(August 2007):107-16. https://doi. org/10.1002/ppul.20755

11. Zakzuk J, Casadiego S, Mercado A, Alvis-Guzman N, Caraballo L. Ascaris lumbricoides infection induces both, reduction and increase of asthma symptoms in a rural community. Acta Trop. 2018 Nov;187:1-4. https://doi.org/10.1016/j. actatropica.2018.07.016 
12. Levin ME, Botha M, Basera W, Facey-thomas HE, Allergy ACN, Al LET. Environmental factors associated with allergy in urban and rural children from the South African Food Allergy (SAFFA) cohort. J Allergy Clin Immunol. 2019;145(1):415-26. https:// doi.org/10.1016/j.jaci.2019.07.048

13. Mbugi EV, Chilongola JO. Allergic disorders in Africa and Africans: Is it primarily a priority? WAO J. 2010;3:175-81. https://doi.org/10.1097/WOX.0b013e3181e1976c

14. Institute of Hydrology, Meteorology and Environmental Studies I. Colombian average climate annual report. [Internet]. [Accessed 2020 Dec 1]. Available from: http://www.ideam.gov.co/ documents/21021/553571/Promedios+Climatológicos++1981+ -+2010.xlsx/f28d0b07-1208-4a46-8ccf-bddd70fb4128.

15. Secretaría de Salud de Santander. Análisis de Situación de Salud con el Modelo de los Determinantes Sociales de Salud Secretaria: Municipio Palmas del Socorro, Santander [Internet]. Grupo de Vigilancia en Salud Pública. Palmas del Socorro, Santander; 2014 [Accessed 2020 Sep 14]. p. 54. Available from: http://web.observatorio.co/publicaciones/ Palmas del Socorro_dg.pdf

16. ESE Centro de Salud, Gobernación de Boyacá, Ministerio de Salud C. Análisis de Situación de Salud con el Modelo de los Determinantes Sociales de Salud Secretaria 2019: Municipio de Soracá, Boyacá.. [Internet]. [Accessed 2020 Dec 1]. Available from: https://www.boyaca.gov.co/SecSalud/images/ Documentos/asis2019/asis_soraca_2019.pdf17.

17. Garcia E, Aristizabal G, Vasquez C, Rodriguez-Martinez CE, Sarmiento OL, Satizabal CL. Prevalence of and factors associated with current asthma symptoms in school children aged 6-7 and 13-14yr old in Bogotá, Colombia. Pediatr Allergy Immunol. 2008;19(4):307-14. https://doi.org/10.1111/j. 1399-3038.2007.00650.x

18. Tillé Y. Sampling and estimation from Finite populations. Wiley, editor. Neuchâtel, Switzerland: Wiley; 2020, pp. 176-177.

19. WHO/UNICEF. Child growth standards in infants and children [Internet]. WHO library. Geneva, Switzerland; 2009 [Accessed 2020Sep 12]. p. 12. Available from: http://apps.who.int/iris/ bitstream/10665/44129/1/9789241598163_eng.pdf?ua=1

20. Mata Fernández $C$, Fernández-Benítez $M$, Pérez Miranda $M$, Guillén Grima F. Validation of the Spanish version of the Phase III ISAAC questionnaire on asthma. J Investig Allergol Clin Immunol. 2005;15(3):201-10.

21. Vidmar SI, Cole TJ, Pan H. Standardizing anthropometric measures in children and adolescents with functions for egen: update. Stata J. 2013;13(2):366-78. https://doi.org/10.1177/15 36867X1301300211

22. Tamhane AR, Westfall AO, Burkholder GA, Cutter GR. Prevalence odds ratio versus prevalence ratio: choice comes with consequences. Stat Med. 2016 Dec;35(30):5730-5. https://doi.org/10.1002/sim.7059

23. Bousquet J, Schünemann HJ, Samolinski B, Demoly P, BaenaCagnani CE, Bachert C, et al. Allergic Rhinitis and its Impact on Asthma (ARIA): achievements in 10 years and future needs. J Allergy Clin Immunol. 2012;130(5):1049-62. https://doi. org/10.1016/j.jaci.2012.07.053

24. Cruz AA, Cooper PJ, Figueiredo CA, Alcantara-Neves NM, Rodrigues LC, Barreto ML. Global issues in allergy and immunology: parasitic infections and allergy. J Allergy Clin Immunol. 2017;140(5):1217-28. https://doi.org/10.1016/j.jaci. 2017.09.005

25. Maizels RM, McSorley HJ. Regulation of the host immune system by helminth parasites. J Allergy Clin Immunol. 2016;138(3):666-75. https://doi.org/10.1016/j.jaci.2016.07.007
26. Hesselmar B, Hicke-Roberts A, Lundell AC, Adlerberth I, Rudin A, Saalman R, et al. Pet-keeping in early life reduces the risk of allergy in a dose-dependent fashion. PLoS One. 2018;13(12):1-13. https://doi.org/10.1371/journal.pone.0208472

27. Frei R, Roduit C, Ferstl R, O’Mahony L, Lauener RP. Exposure of children to rural lifestyle factors associated with protection against allergies induces an anti-Neu5Gc antibody response. Front Immunol. 2019;10:4-8. https://doi.org/10.3389/fimmu. 2019.01628

28. Martinez FD. Childhood asthma inception and progression: role of microbial exposures, susceptibility to viruses and early allergic sensitization. Immunol Allergy Clin North Am. 2019;39(2):141-50. https://doi.org/10.1016/j.iac.2018.12.001

29. de Fernandes SSC, de Andrade CR, Alvim CG, Camargos PAM, da Ibiapina C. Epidemiological trends of allergic diseases in adolescents. J Bras Pneumol. 2017;43:368-72. https://doi. org/10.1590/s1806-37562016000000255

30. Alcaldía de Palmas del Socorro. Plan de Desarrollo Municipal Palmas del Socorro. 2011; pp. 1-317. [Internet]. [Accessed 2020 Dec 1]. Available from: https://candidatosconlaeducacion.esap.edu.co/handle/123456789/13045

31. Banco Interamericano de Desarrollo, OPS I de VS. Un Llamado a la Acción: Hacer frente a helmintos transmitidos por el suelo en América Latina y el Caribe. 2011;38. [Internet]. [Accessed 2020 Dec 1]. Available from: https://www.paho.org/hq/ dmdocuments/2011/lac-report-esp-final-3-2011.pdf

32. Giraldo-Ospina B, Ramírez-Hoyos LS, Henao-Nieto DE, Flórez-Salazar M, Parra-Londoño F, Gómez-Giraldo EL, et al. Estimación de la prevalencia de parásitos intestinales en niños de dos comunidades colombianas. Biosalud. 2015;14(2):19-28. https://doi.org/10.17151/biosa.2015.14.2.3

33. Bailey C, Lopez S, Camero A, Taiquiri C, Arhuay Y, Moore DAJ. Factors associated with parasitic infection amongst street children in orphanages across Lima, Peru. Pathog Glob Health. 2013 Mar;107(2):52-7. https://doi.org/10.1179/2047773213Y. 0000000073

34. Leonardi-Bee J, Pritchard D, Britton J. Asthma and current intestinal parasite infection: systematic review and meta-analysis. Am J Respir Crit Care Med. 2006;174(5):514-23. https://doi.org/10.1164/rccm.200603-3310C

35. Dennis R, Caraballo L, García E, Caballero A, Aristizabal G, Córdoba $\mathrm{H}$, et al. Asthma and other allergic conditions in Colombia: a study in 6 cities. Ann Allergy Asthma Immunol. 2004 Dec;93(6):568-74. https://doi.org/10.1016/ S1081-1206(10)61265-3

36. Czarnecka M, Baran A. Epidemiology of atopic dermatitis in Europe. J Drug Assess. 2019;8(1):126-8. https://doi.org/10.108 0/21556660.2019.1619570

37. Peñaranda A, Garcia E, Barragán AM, Rondón MA, Pérez A, Rojas $M X$, et al. Factors associated with allergic rhinitis in colombian subpopulations aged 1 to 17 and 18 to 59 . Rhinology. 2016;54(1):56-67. https://doi.org/10.4193/Rhin14.234

38. Fsadni C, Fsadni P, Montefort S, Fava S. Food consumption and the risk of childhood allergy. Asia Pac Allergy. 2018;8(4):1-8. https://doi.org/10.5415/apallergy.2018.8.e35

39. Pesko MF, Robarts AMT. Adolescent tobacco use in urban versus rural areas of the United States: The influence of tobacco control policy environments. J Adolesc Health. 2017;61(1):706. https://doi.org/10.1016/j.jadohealth.2017.01.019

40. Strom MA, Silverberg Jl. Associations of physical activity and sedentary behavior with atopic disease in United States children. J Pediatr. 2016;174:247-253.e3. https://doi. org/10.1016/j.jpeds.2016.03.063 